\title{
DEL REDUCCIONISMO COMO TEMA DE CRÍTICA FILOSÓFICA
}

\author{
Enrique Puchet C.*
}

\begin{abstract}
SÍNTESE - No Vocabulaire technique et critique de la philosophie, de André Lalande (5. ed., 1947), lê-se: "quando se fala em reduzir um fato a certos elementos tem-se em conta seja uma limitação e um empobrecimento inaceitáveis, seja, pelo contrário, uma simplificação útil e legítima que conserva o essencial do fato em questão". O modo de pensar reducionista, de que se ocupa este artigo, corresponde à primeira daquelas acepções e como tal é criticado com o auxilio de dois autores clássicos, em ordem não cronológica: Hegel e Dante.

ABSTRACT - A sentence in the book Vocabulaire technique et critique de la philosophie, by André Lalande (5th edition, 1947), states: "When we talk about reducing a fact to certain elements, we consider either inacceptable poverty and limitation or, conversely, legitimate and useful simplification that maintains the essence of the fact itself". This simplified way of thinking is criticized by two classical authors who lived in different periods: Hegel and Dante.
\end{abstract}

\begin{abstract}
"Empieza, con lo cualitativo como tal, un nuevo orden..."
"Pero se ha mostrado que las variaciones del ser general no son sólo el traspasar de una magnitud a otra magnitud, sino un traspaso de lo cualitativo a lo cuantitativo y viceversa, un devenir otro, que es un interrumpirse de lo gradual, y el surgir de un nuevo cualitativo, frente a la existencia antecedente" (Hegel, Ciencia de la Lógica.)
\end{abstract}

Los problemas de modo (o método) de pensar, que ocuparon de preferencia a los modernos (por ejemplo, en el intenso siglo XVII), son también hoy objeto de legítima inquietud para los filósofos - lo mismo si se entiende filosofia en sentido técnico que si se están considerando sus efectos, más difundidos, en el espiritu público. De esto último hace falta - creemos - hablar com insistencia - tiempos de recuperación democrática deben poner el asunto en sitio privilegiado - y los centros de educación, no en último lugar los universitarios, deberian pensarse como involucrados en la extensión, al gran público culto, de los análisis, del sesgo mental que los especialistas cultivan, a veces, con desmedida delectación. El 'modo de pensar'1 está siempre presente, expreso o tácito. La formulación de los partidarismos políticos lo lleva implícito en todo momento; las relaciones del mundo del trabajo exteriorizan los subyacentes abordajes de la relación humana en general, tanto más si consisten en negociaciones; el propio medio de la vida personal, mucho más 'ideologizado' de lo que se supone, se alimenta - para crecer o para debilitarse - de concepciones acerca de generaciones sucesi-

* Departamento de Historia y Filosofia de la Educación. Universidad de la República, Montevideo - Uruguay.

1 Con el signo: '...' indicamos en este ensayo que deseamos hacer un uso libre de la expresión así enmarcada.

\begin{tabular}{|l|l|l|l|l|l|}
\hline VERITAS & Porto Alegre & v. 40 & $\mathrm{n}^{2} 157$ & Março 1995 & p. 67-77 \\
\hline
\end{tabular}


vas, formación, heterosexualidad... ¿Es manía de (hiper-) intelectualización persistir en hablar de pensamiento, y del modo o estilo de ejercitarlo, cuando parece tratarse, más brutal o más banalmente, de vencer, trabar, sujetar, acoger (o no) con simpatía? No lo es: hay una modalidad humana de practicar tales operaciones. En último término, siempre estamos abocados a justificaciones, teorizaciones, coherencias bien o mal mantenidas, etc - y estas cosas pertenecen al orbe de las operaciones intelectuales y remiten, finalmente, a algún esquema básico que todos afirmamos tener buenas razones para sustentar. Hombres comunes, hacemos teoría - ética y lógica - sin saberlo. De dar malas razones nos avergonzamos, antes o después, seres discursivos como somos. (En esto de acogerse a razones válidas, nos advierte Kant que no hay opción posible: "Si la razón no quiere estar sometida a la ley que ella se da a sí misma, entonces ha de doblegarse bajo el yugo de las leyes que le da algún otro".)

Por otro lado, es preciso cuidarse del malentendido que ve en el uso público una forma menor, o más débil, de la ocupación con ideas, la cual sólo sería rigurosa (cientifica) en el santuario de los institutos especializados. Un malentendido de tradición académica propensa a autoalimentarse. Atender a empleos cotidianos del discurso no significa abandonar el rigor de los científicos ni privarse de la indispensable compañía de los que han construído una tradición - ésta, sí, respetable - de análisis intelectual exigente (como debe suponerse, viceversa, que el cultivo profesional no se cierra a los desafíos de la existencia de todos los días). Porque en compañia de filósofos - más en general, de intelectuales reflexivos - necesitamos caminar para saber con seguridad qué perspectiva estamos adoptando; sin ignorar que el abuso de andadores merece el reproche que todos tenemos en mente: cultura, por carencia de originalidad.

Resolvámonos a comenzar con una tal apelación a los modelos. Desde ellos, por lo demás, podrá re-comenzar aquel a quien nuestra incipiente exégesis deje descontento.

El "modo de pensar" se traduce habitualmente en observaciones como de paso que los grandes espíritus (tolérese la retórica) siembran como consignas para no olvidar. Tienen el sabor de las actitudes "de época": las convicciones del momento se reflejan en ellas; consecuentemente, en la medida de su autenticidad, remiten a otros tiempos en que los hombres dejaron de ser conducidos por intuiciones de ese orden verdaderos hilos conductores - y pasaron a orientarse por las certezas de una nueva ciencia y de una nueva sociedad. Un estimulante juego de influencias mutuas se entabla, en cada momento, entre esquemas intelectuales y condiciones epocales; un orden de resonancias y desmentidos se construye a lo largo de los instantes de la História. La educación, o buena parte de ella, reposa en la confianza de que tal diálogo de cosmovisiones sirva para nuestra ilustración en el presente, necesitado de vislumbres enriquecedoras.

Consideremos, así, la instructiva dualidad que se desprende del siguiente paralelo, que recorre, en números redondos, 330 años (de nuestra parte, aquí, toda intención erudita está fuera de cuestión).

- (Dante Alighieri, hacia 1308): "Empleo el término 'hermana' en sentido metafórico, porque así como se llama hermana a la mujer engendrada por un mismo padre, así el hombre puede llamar 'hermana' a la obra hecha por un mismo autor, pues toda acción es, en cierto modo, una generación" (nosotros subrayamos).

- (R. Descartes, 1637): "Sitôt que j'eu acquis quelques notions générales touchant la physique... elles m'ont fait voir qu'il est possible de parvenir à des connaissances qui sont fort utiles à la vie; et qu'au lieu de cette philosophie spéculative qu'on enseigne dans les écoles, on en peut trouver une pratique, par laquelle, connaissant la force et les actions du feu, de l'eau, de 
l'air, des astres, des cieux et de tous les autres corps qui nous environnent, aussi distinctement que nous connaissons les divers métiers de nos artisans, nous les pourrions employer en même façon à tous les usages auxquels ils sont propres, et ainsi nous rendre comme maitres et possesseurs de la nature" (el subrayado es nuestro).

Una bella confrontación de puntos de vista, no obstante la concisión del primero, que proviene de El convite, ${ }^{2}$ y el carácter mucho más explícito del segundo, extraído del Discours de la méthode (parte VI). El proyecto utilitario de la modernidad, su opción por el mecanicismo, se nos hacen presentes en franco contraste con la visión de la naturaleza desde el interior, tan perceptible en las acciones interpretadas como generaciones, según el persuasivo lenguage dantesco. Los textos citados no dejan dudas sobre la oposición: por un lado, ver el arte como naturaleza; por otro, ver la naturaleza como arte. (Valdría la pena preguntarse de qué lado cae nuestro modo de ver el obrar humano en tanto que asunto de insumos y de productos).

Señalemos, además, que un testigo tan válido en esto como K. Marx aparece admitiendo, en un pasaje de El capital en que se transcribe el texto cartesiano, que hay efectivamente aquí un tópico de método (Denkmethode), un fragmento de historia intelectual y, por lo tanto, de orientación mental, del que es imposible desentenderse cuando se quiere hacer de Descartes el portador de una cosmovisión. No sólo viene el filósofo, que es también físico y geómetra, en la cresta del ascenso de la burguesía europea, a la que le es connatural concebirlo todo bajo la relación del mecanismo; sino que, si de veras nos importa comprender, tendremos que hacernos cargo de ese círculo de ideas - con su coherencia interna y ou apertura a otros ámbitos (la Metafísica, la Moral) - que el pensador moderno, cuidadoso de su propia evolución vigorosamente personalizada, define y explora. Las formas de entender las cosas, la "dirección del espíritu", no son subproductos indiferentes que podríamos poner de lado, como sombras, mientras nos apoderaríamos del duro hueso de las realidades exteriormente comprobables. Una mente reexamina su cultura y totaliza sus experiencias, grandes e pequeñas. Descartes es un representante estamental y, al mismo tiempo, un pensador viviente (auto-biografiable.)

\section{1}

La polémica en torno al enfoque o manera de pensar reduccionista ha sido constante en la História de la Filosofía. Un conocidísimo pasaje del Fedón platónico (o, quizás, la obra entera) plantea las cosas con acuidad al censurar la pretensión, de evidente sesgo reduccionista, de que Sócrates, condenado, haya afrontado su suerte sólo porque su motricidad como ente corpóreo permite tales o cuales desplazamientos (o privación de ellos). La suposición es grotesca, pero el esquema básico no ha dejado de operar. Reaparece toda vez que se toman las condiciones por causas directivas, es decir, cuando se suprime el sujeto que valora y actúa. Un paso imperceptible se verifica entre: "no lo haría si no contara con..." y: "lo hace precisamente porque..." En Platón, aun con independencia del aliento espiritualista, sin duda dominante en el diálogo, lo esencial del reproche queda a la vista: la integridad de la conducta, a la vez valorante y físicamente canalizada, resulta comprometida, convertida en sinsentido, si el complejo actuante se reduce al esquema de la mecánica corporal, indispensable pero mudo sobre finalidades.

2 Tratado III, Cap. IX. 
Como no procuramos hacer trabajo de historiador baste con este antecedente clásico y, como adición, otra simple alusión, referida a una línea de pensamiento que los expositores no acostumbran a construir. Se trata de la tendencia que nace con la renovación romántica (ver Shelley, Defensa de la poesia, pasa por la critica goetheana a los modelos artificialistas acerca del acaecer natural y de la invención humana, y conduce a la insistente denucia bergsoniana de los procedimientos asociacionistas ("atomismo", mental u otro) que obstan a la percepción de lo nuevo.

Es lo cierto que la milenaria dicusión asi entablada ha servido para perfilar, en clima de polémica, un estilo intelectual del que consignaremos alguno rasgos que nos parecen decisivos.

Caracterízase el reduccionismo por sostener - o presuponer - que lo ya apresado conceptualmente $y$, por otro tanto, más fácilmente domeñable y más simple, proporciona la clave de cualquier otra realidad que venga a agregarse a lo que ya "se conoce". En último término, implica que las explicaciones - y los modos de obrar - pueden ser reconducidos, sin residuo, a un cierto número de principios a cuya luz todo advenimiento, por inusitado que sea, es sólo oportunidad de aplicación.

La reducción se perfecciona si, a partir de la óptica vieja se entiende posible formular leyes, enunciados que permitem descontar el acaecer y situarlo como. "caso". Usualmente, la forma legal versa sobre lo captable "desde fuera" y, por ende, exime de un nuevo esfuerzo, "interior", de comprensión. La prevalencia de lo cuantitativo sobre lo cualitativo subyace a esta postura para la cual hablar de la singularidad de los procesos es un abuso de la retórica intuicionista.

Para perfilar desde otro ángulo el mismo estado de espíritu, diremos que el reduccionista se beneficia de un peculiar malentendido acerca de la relación de fundamento a fundado. A saber: malinterpreta este nexo al asumir que el no poder presentarse A sin que B le sirva de antecedente o ámbito generador implica que no hay en A (subrayemos el giro) nada más que lo que B ya contenía. Ilustremos nuestro intento crítico con un ejemplo de experiencia diaria: es cierto que no se movería el operario, que sobrevive con la prestación de ocasionales servicios, a menos de hallarse colocado en situación de ser retribuído por determinados rendimientos. Pero de ahi no se infiere que, entonces, cualesquiera valoraciones surgidas en el proceso del trabajo ejemplo característico: cierto sentido del honor, que le hace negarse a anticipar el precio final como si hubiera de temerse un exceso deshonesto - "no sean más que" esperable traducción del condicionamiento inicial (en tal caso, el honor seria interpretable como astucia bien calculada), ni merezcan, por ende, ningún esfuerzo de descripción que las tome por tema en si mismo abordable.

Lo que aseveramos es que, al adoptarse tal enfoque, ocurre un trueque indebido: lo que es condición sine qua non se vuelve razón de ser en cuyos términos ha de interpretarse todo lo que sobre su condicionamiento se construye. No sin que el paralogismo incida muy directamente en actitudes prácticas que deben merecer nuestra atención. Cierto escepticismo ( 0 cinismo?) reinante acerca de lo que presuntamente mueve los hombres, gravita en ese sentido reductor e incomprensivo. (Incidentalmente: aquello, consabido, de que "todos los hombres tienen un precio...", es verdadero con tal que se mantenga en un plano tan abstracto como para tornarse en... inoperante; consecuencia que ha de disgustar al realista que pronuncia el docto principio como si estuviera hundiendo sus manos en la efectividad más concreta del mundo). 
Se presiente que la ardua cuestión de las superstructuras está involucrada en esta discusión que, como vemos, no carece de efectos prácticos. ${ }^{3}$

\section{1}

Como más arriba dijimos, nos es preciso caminar junto a quienes han alcanzado una aprehensión más honda de sesgos intelectuales como el que nos ocupa. No querrá decir que la perspectiva que aquí adoptamos haya de serles atribuída a los escritores - porque de escritura ha de tratarse, querámoslo o no - de los que este esbozo va a servirse en adelante. ${ }^{4}$ Em particular: no significa que eso que recortamos en un autor como digno de ser pensado aparezca tal cual en la fuente a que recurrimos. Un tema (¿es, el presente, fructífero?) nos sale al encuentro una y otra vez a lo largo del tiempo; logo que él parece encerrar hace leer de una determinada forma a los recurrentes tuteladores de las horas de estudio: éstos, sin embargo, no deben quedar comprometidos por preocupaciones que, acaso, se vinculan meramente con esa propensión a 'ver a través' que algunos hombres llevan a la experiencia cotidiana no más que por defecto de plenitud (o, dicho con lenguaje ilustre: por incapacidad para practicar el ama et fac quod vis).

\section{1}

En Hegel, tanto en la Ciencia de la lógica como en las Lecciones sobre la filosofía de la historia universal, cabe rastrear elementos que coadyuvan a nuestro actual propósito. Hablamos cautamente de elementos que contribuyen, no, en absoluto, de hacernos cargo del sistema como tal, demasiado imponente y caviloso para ser apropiado (y, aun, entendido) en nuestros días y con nuestros recursos. Una lectura no proclive a las exageraciones idealistas, que al reiterarse terminan por perder efecto - una 'lectura intersticial', como nos gusta llamarla - deja ver en el gran filósofo un extremo cuidado por preservar la especificidad de los grados sucesivos de la escala ontológica de que se trate; por lo tanto, una sugestiva resistencia a las 'tracciones desde abajo', desde lo más general - em suma: una clara tesitura antirreduccionista. Y esto es, precisamente, lo que va a permitirnos andar unos pasos en su prestigiosa e incómoda compañía.

Nos referimos, em primer lugar, a Lógica, Libro $1^{\text {ero }}$. ("La doctrina del ser"), comienzo de la $3^{\text {era }}$. Sección ("La medida").

En este locus, hallamos una fecunda consideración de este tipo: Respecto de la relevancia del punto de vista de las leyes físicas atenidas a la cantidad y a la medida, la realidad natural y, más todavia, la espiritual, muestran la progresiva pérdida de per-

3 Efectos prácticos, incluidos los que se sitúan en el campo de la formación educativa, objeto de nuestra particular preocupación. Obsérvese cómo, simplificar las cosas en el sentido del economicismo trae como consecuencia una visión empobrecedora e inexacta como la que refleja esta apreciación: (según Locke) "Si se ve perturbado el ininterrumpido proceso de beneficios económicos, los hombres tienen el derecho de resistir al poder político". Ahora bien: nos guste o no, Locke no se propone como alguien que monta guardia (teórica) al servicio de alguna liga subversiva de defensa del lucro empresario. Distorsiones por el estilo abundan en nuestro medios.

4 Si hiciera falta abogar en favor de una reflexión informada nos gustaría citar estas expresiones recientes de P. Ricoeur, sobrias y atinadas como suelen serlo las suyas: "Es en los textos que se fundan los intercambios primordiales entre el pasado de las tradiciones y el futuro de nuestras esperanzas más enérgicas, entre las cuales hay que contar nuestras utopias" (artículo en "Libertação/Liberación, CEFI, Brasil, año III, 1993). 
tinencia de esquema mecanicista (lo que no es lo mismo que la abolición de éste); de suerte que, en el plano superior, ni puede afirmarse que el inferior haya quedado extinguido, ni, menos aún, pretenderse que sea adecuado un modo de ver, cualquiera sea, que se acoja a la consigna no más que. A base de lo ya sabido, sabemos paulatinamente menos conforme avanzamos en complejidad; según se asciende, el enfoque previo captura con menor integridad lo característico del plano al que accedemos; $\mathrm{e}$, ignorarlo, conduce a saber mal.

Repetimos que esto es lo que encontramos en una cierta lectura del dificultoso pasaje hegueliano; una exégesis técnica pediría reintegrar la (proverbial) intrincación del sistema. En lo que nos interesa, se trata de una regla de dirección del espíritu, como se hubiera dicho dos siglos antes de Hegel. Y, comoquiera que nos importan los usos corrientes de la inteligencia, la recomendación que derivamos ha de revestir la banalidad de lo cotidiano, tal como resplandece en el enunciado. Es de buena lógica, entendiendo por tal la que se propone fidelidad a los hechos, desconfiar de aquellos argumentos que se introducen al amparo del lema: "al fin y al cabo, todo es simple cuestión de..." La técnica filosófica no sale enriquecida con esta reutilización del tema hegueliano, pero tal vez sí se favorece el propósito pedagógico de mejorar el empleo ordinario del entendimiento.

Conviene atender al pormenor de la argumentación hegueliana. ${ }^{5}$ Recordemos que el hilo conductor es la progresiva irrelevancia, la penuria del abordaje físico centrado en consideraciones cuantitativas cuando es cuestión de interpretar realidades más y más complejas.

a) A nivel de los mecanismos, triunfa el punto de vista de la medida. Ésta encierra casi todo (habrá una restricción) lo que podemos expresar al respecto. Los entes están aquí como de-singularizados, de suerte que "lo corpóreo concreto es sólo la misma materia abstracta" (trad. de A. y R. Mondolfo, vol. I, p. 424; ed. Hachette); aquí, "las diferencias cualitativas tienen esencialmente por su determinación lo cuantitativo".

5 Vale la pena tener a la vista, asimismo, el revelador parágrafo 380 de la Enciclopedia de las ciencias filosóficas, del que extraemos el siguiente fragmento:

"(A diferencia de la naturaleza exterior), las determinaciones y los grados del espiritu, en cambio, no son esencialmente sino momentos, estados, determinaciones en los grados de desarrollo más altos. Esto resulta de la circunstancia de que, en una determinación inferior, más abstracta, el elemento superior se muestra ya como existiendo empíncamente; por ej., en la sensibilidad se encuentra todo el elemento espiritual superior como contenido o determinación concreta. Para una consideración superficial, pues, ese contenido religioso, moral, etc. puede parecer que tiene esencialmente su lugar e, incluso, su raiz en el sentimiento, que no es más que una forma abstracta; y puede parecer que es necesario considerar sus determinaciones como modos particulares de la sensibilidad. Sin embargo, sería también necesario, al atender a los grados inferiores, y para deslindarlos según su existencia empíica, evocar los grados superiores en que no existen más que como formas y, de este modo, anticipar un contenido que sólo más tarde se hace presente en el desarrollo (ej.: la conciencia en el despertar natural, el entendimiento en la demencia, etc.)".

Lo que se puede decir, procediendo con cautela, es que este parágrafo sin duda contiene: (1) una nitida postulación antirreduccionista; (2) una aparente afiliación al tradicionalismo filosófico y, en el fondo, un correctivo - difícil de asimilar, dificil de practicar - para la tendencia, tan arraigada, a indagar de dónde (de qué fuente previa) ha de provenir lo nuevo e supenior.

Este último punto mereceria renovadas reflexiones. Contentémonos con otra indicación textual. Estimamos prometedor de buena cosecha volver a Ciencia de la lógica, loc. cit., cap. II, B., Nota; especialmente el parágrafo que comienza con esta sugestiva declaración: "Todo nacimiento y muerte, en lugar de ser una gradualidad progresiva, son antes bien una interrupción de ella, y un salto desde la variación cuantitativa hacia la cualitativa" (ed. cit., vol. I, p. 474). 
(Hay, empero, un factor perturbador, y es preciso tomarlo en cuenta por respecto al texto. Hegel dice que "esta determinación de magnitud del material abstracto se halla perturbada, ya en lo físico, por la pluralidad y un conflicto consiguiente de las cualidades". ${ }^{6}$ Traduzcamos, a los fines de la presente explanación: la visión más abstracta de todas debe aún plegarse a la intrusión de la divesidad cualitativa, inclusive en el campo en que su poderío aparece más incontrastado).

b) Si, todavía dentro del orden natural, pasamos a lo orgánico, no sólo nos sale al paso un factor perturbador, sino que, ahora, "la medida se ve subordinada a relaciones superiores" (p. 425). Ahora, en efecto, aunque sigamos midiendo partes; aspectos 0 variables, importan primordialmente las relaciones en un todo conexo, "proporcionado" (anticipando fenómenos de cultura: Paris o Londres eran grandes ciudades medievales sólo respecto de los hechos de urbanización de la época). Medir un miembro es in-significante salvo si se mantiene la referencia a los restantes: "las proporciones del cuerpo humano son relaciones constantes de tales cuantos". Puesto que lo dominante es esa referencia mutua, la indicación de medidas aisladas es inexpresiva, extrínseca.

Esta paulatina pérdida de relevancia se muestra asimismo en el caso del movimiento. Sobre los cuerpos celestes es posible construir una teoría deductiva exhaustiva. Aqui, "el movimiento es movimiento libre, determinado sólo mediante el concepto, y las magnitudes, por lo tanto, dependen sólo del mismo concepto". La novedad que involucra lo orgánico es la 'espontaneidad', la 'motivación'; dimensión nueva según la cual el mero movimiento - esquema abstracto - aparece como arbitrario (sic). A menos que en el cambio de lugar de un ser vivo se consideren los factores de búsqueda y evitación, los desplazamientos son extrínsecos y carecen de sentido: así interpretamos la calificación de arbitrarios que Hegel les atribuye; ${ }^{7}$ como es normal en esta dialéctica vertiginosa, es necesario reintegrar los elementos implícitos.

c) Pero lo más significativo se nos presenta al acceder al 'reino del espíritu'. Ahora se vuelve enteramente manifiesto que el enfoque propio de la medida, si se lo propone por sí mismo, si se pretende que rija como suficiente, no da en el blanco.

Los dos primeros ejemplos que Hegel utiliza provienen de la Historia, pertenecen al dominio del "espíritu objetivo". Llenan apenas unas líneas en la Lógica, pero contienen una lección perdurable. El filósofo hace notar que, sin duda, determinados montos relativos a la demografía ("una cierta magnitud del Estado") han de ser tomados en consideración como constantes que subtienden a estructuras también determinadas de índole político-social. Digamos que tal o cual forma institucional supone que el marco de lo enumerable, del cuanto, alcance niveles que, por definición, caen en la esfera del más o menos. Así en la Antigüedad clásica, el advenimiento de las formas republicanas (democráticas: valor cualitativo) sólo pudo tener lugar en ciertas condi-

6 ¡Cuánto más tendrán que esperar sorpresas los planificadores de la sociedad o de la educación!

7 A efectos de mantener a la vista las derivaciones en el campo de la conducta calificable como buena o mala - tema en el que no dejamos de pensar - nos resulta significativo que existan, no una, sino dos formas de marrar una interpretación adecuada de 'lo que sucede' en materia de comportamientos de tal modo valorables. Las llamariamos 'incomprensión desde abajo' e 'incomprensión desde arriba' (moralizante). He aquí el espectacular fait divers: la indignada joven remueve violentamente el aire y hace estallar los oídos de sus mayores con la estridencia de un portazo que censura. Pues bien: el obvio componente motivacional - clave de la situación - es pasado por alto, tanto por la impasible versión cinética del acontecimiento (un cuerpo que se desplaza entre cuerpos como por la versión moralizadora que lo declara inconcebible y se dispone a sancionar sin hacerse más preguntas. El hecho es anecdótico, el enfoque que de él se haga no lo es. 
ciones que refieren al orden de las cantidades (la presión por la democracia implica nuevos contingentes pluralmente dotados: los hoplitas son más numerosos que los guerreros nobles del antiguo régimen); o, con otro caso, en la sociedad civil desarrollada (concepto sociológico no cuantitativo) las cantidades de miembros de las diferentes profesiones guardan alguna relación traducible en número.

Insistamos sobre esto, porque la claridad acerca del lugar de lo cuantitativo es una condición para captar, luego, la tesis de que su pretensión de prevalecer como decisiva y autosuficiente es indebida. Pensar las repúblicas griegas en términos de pluralidad numerable - de muchos respecto de lo anterior - contiene una verdad indudable: las ciudades-Estados con igualdad ante la ley no han nacido de acuerdos caballerescos entre individuos singularizados (este tipo de pacto de pocos es más bien aristocrático, homérico), sino del anonimato propio de masas humanas que han alcanzado un cierto quantum. Sin embargo - y aquí surge la reflexión fundamental que corrige extralimitaciones - "esto, escribe Hegel, no da ni leyes de medidas ni formas propias de ellas": rotunda declaración en el sentido de que la reducción a términos de cantidad es una vía errónea y que, por conseguiente, hay un sofisma en aseverar que, puesto que el lado numérico importa sin duda, entonces, "todo es una cuestión de número". La comunidad democrática sigue siendo una realidad para describir en sus valores, en sus propósitos, aun después de reconocer, como corresponde hacerlo, que sólo pudo darse en la Historia en relación con una extensión de las aspiraciones a ocupar un lugar bajo el sol. (Otro ejemplo: lo mismo se desprende del siguiente modo de caracterizar el movimiento en favor de las franquicias burguesas, en la Edad Media: "Cuando en el siglo XII se encontraron más ricos los habitantes, empezaron a desear un régimen más regular". La apreciación se encuentra en uno de los clásicos manuales de Ch. Seignobos, hoy olvidados.)

Em suma: la pluralidad numerable no cancela la axiología; es, sin embargo, lo que postula el eslógan reduccionista que afirma "no tratarse más de que..."

Por cierto que asi nos vemos conducidos a difíciles problemas de interpretación. Lo prueba el hecho de que, ahora mismo, sea necesario desarrollar también una reflexión - 0 , al menos, un comienzo de ella - que parece estar en pugna con la que acabamos de presentar.

Existe un estilo de razonar que presume - con el beneplácito de nuestros oidos aquiescentes - la independencia, sumamente improbable del valor de las instituciones (v. gr. centros educativos) respecto de su dotación en términos cuantitativos. Se oye decir: "no somos peores ni importamos menos por el hecho de ser pocos...".; curiosa manera de apreciar el mérito de actividades que, por su naturaleza, están destinadas a diseminarse. Esto puede ser cierto si se está hablando de un instituto de investigación (aunque, en tal caso, habrá que pasar a hacer referencia, necesariamente, a laboratorios bien pertrechados y a nutridisimas bibliotecas: he aquí que el quantum ha reaparecido). Es claro, en cambio, que el argumento falla si es cuestión de actividades educativas de transmisión e influjo en el medio; puesto que, entonces, el monto de la matrícula pone al descubierto, prima facie, la aceptabilidad social de la "oferta". Y si esto merece ser discutido, como toda cosa, no puede serlo, en un análisis fructuoso, sin descartar el obstáculo de una rigida adhesión a cualidades inverificables, a valores cuya dignidad radicaria en escasa efectuación.

En verdad, la elocuencia del discurso cualitativista que encaramos con ánimo crítico extrae su fuerza de la amenaza del burdo reduccionismo siempre dispuesto a pronunciar su famosa contraseñá: "no más que". Pero importa advertir que el exacto opuesto de un reduccionista es... otro reduccionista (ver más arriba, nota 7). Lo que tenemos que procurar es romper el círculo.

Por último, hay también algo que decir en la esfera del "espíritu subjetivo", mentado esta vez por Hegel como "lo espiritual como tal". El texto que examinamos deja ver una objeción a los avances de la sicometría, que ya se insinuaban y que no han cesado de reaparecer. El sentido común no anda descaminado. No es un desatino (y, 
por otra parte, ¿cómo evitarlo?) aludir a grados diferentes de fuerza en lo anímico: del carácter, de la imaginación, de la percepción, etc. Tiene pleno sentido referirse a voluntades más o menos dominantes. Lo cuestionable surge cuando se da el paso - ilusorio - de procurar medidas precisas: entonces se descubre que "la determinación no va más allá de ese /elemento/ indeterminado de fuerza o debilidad". El afán de cuantificación echa a perder lo que la apreciación global tiene de verosimil y de utilizable.

No únicamente en el locus examinado (se tendrá en cuenta nuestra nota 5 , in fine) proporciona la Lógica hegueliana ocasión de discutir, al servicio de nuestros fines, el asunto que nos concierne, el cual, en palabras del autor sobremanera explícitas, reside para él en "la conexión entre la naturaleza cualitativa de una existencia y su determinación de cantidad en la medida" (p. 438). En la confusísima exposición acerca de la afinidad electiva - ver "Doctrina del ser", 3era. sección, cap. II - es posible recuperar puntualizaciones persuasivas acerca de aquellas explicaciones reductivas que acaban por eliminar eso mismo que presumo de estar explicando. Como es habitual, el aspecto metodológico, siempre más fecundo, se desprende de la oscuridad en que se halla envuelta la discusión.

Sin embargo, nuestro análisis conservará mayor coherencia si nos dirigimos a las Lecciones sobre la filosofia de la historia universal, obra que, como sabemos, le es atribuída en base a anotaciones de oyentes confiables (conocemos la versión de J. Gaos, 2 vols., ed. Revista de Occidente).

\section{2}

La primera observación que interesa tiene que ver con un tema al que el debate económico de estos días nos ha acostumbrado: el de la relación entre crecimiento y desarrollo. A través de esta actualización quisiéramos contemplarlo.

Se trata de las magnificas construcciones babilónicas, restablecidas por la investigación histórica. En principio, Hegel no vacila en reconocer una conexión entre "calidad de vida" y grandiosidad de las expresiones materiales. Afirma: "El gran valor de aquella comunidad de vida puede medirse por el gasto que hacía en sus construcciones" (Lecciones, vol. I, p. 369). Nos preguntamos si es esto todo lo que piensa. La grandiosidad de templos y locales civiles, ¿es índice seguro de nivel cualitativo, de manera que sea concebible una relación necesaria entre ambos, lo que permitiría apresar lo cualitativo reduciéndolo a términos de acondicionamiento físico? No; no es esta una cuestión que se deje simplificar a tal extremo. Algo que el texto contiene un poco más adelante demuestra que Hegel (y sus seguidores) ven las cosas con más integridad y piensan, de aquella medida, lo que sin duda el filósofo cree de la medida en general: que constituye un marco exterior indicativo que, ni puede ser contado como unívoco y decisivo, ni tampoco excluído como irrelevante.

En efecto, a propósito de las ciudades griegas del Asia Menor, enfrentadas a la amenaza persa, las Lecciones señalan que la opulencia fue un obstáculo para que adoptaran enégicas decisiones salvadoras (ejemplo: pactar entre si alianzas superando el particularismo, o, inclusive, buscar una nueva patria en otro sitio). La magna disposición de recursos materiales no anduvo de par con rasgos no cuantitativos que indudablemente refieren a la "calidad de vida": las relaciones interestatales, el amor a la independencia. Sólo la magnitud del peligro - no, por tanto, una apreciación juiciosa de las posibilidades - hizo que "salvaran el pellejo", sin duda tardiamente. La prosperidad económica había enervado el temple vital, resorte de las grandes determinacio- 
nes. No es, pues, cierto que todas las formas del poderío se acompañen, por así decirlo, biunivocamente. De paso, el fragmento considerado prueba que la visión de Hegel no padece macropsia - en particular, que no padece debilidad ideológica por las grandes concentraciones del poder.

El pasaje respectivo es digno de reproducirse:

"A esta unión no podian llegar aquellas ciudades, que estaban animadas de grandes rivalidades y vivian en continua disencción; y para tomar la heroica resolución de abandonar sus hogares por la libertad, no tenían, en la embriaguez de la abundancia, la energía suficiente. Sólo cuando estuvieron a punto de ser sometidas por los persas, resolviéronse algunas ciudades a trocar lo cierto por lo incierto conservando asi el sumo bien, la libertad" (p. 373).

Expresado en el estilo de la Lógica: la cualidad entraña un orden nuevo. No se da con prescindencia de un marco cuantitativo, no nace por simple virtud de éste. Atender al solo crecimiento (¿no es la teoría de "agrandar la torta"?) es "mantenerse adheridos unilateralmente a la abstracta determinación del cuanto": así se expresạ Hegel en la Ciencia de la lógica (parte citada, sec. $3^{\text {era }}$, cap. I, A), en un lugar en que sabe sacar partido del "sofisma del calvo" para aleccionar a los que no perciben el cambio cualitativo en el curso del adicionar o el sustraer.

No está de más haber dejado constancia de que el gran idealista no viene en apoyo, ni de liberticidas que declaran no creer más que en la ordenada eficiencia, ni de sostenadores de un crecimiento fin en sí.

De la implacable aridez hegueliana, algo atenuada en las Lecciones, va a resarcirnos la gracia didáctica de Dante Alighieri. Se tratará sólo de mostrar rápidamente cómo el Dante filósofo (en verdad, un converso a la Filosofía), razonando en Il convivio (El convite, trad. de J. L. Gutiérrez-García; B.A.C., 1965), Tratado III, caps. ii-iii, enuncia con nitidez la verdad que el reduccionista desconoce; a saber: el que A sea fundamento de B no significa, sino más bien al contrario, que el primero vuelva superfluo al segundo, absorbiéndolo. Que B suponga a A como el seno en que emerge quiere decir tanto la condicionalidad de B como su especificidad. (Volvemos a pensar en el material histórico, en el contexto evocado más arriba: "A medida que aumentó la población, el señor dejó que resolvieran sus asuntos los habitantes sin excluir a los artesanos, descendientes de siervos, acabando por limitarse a pedir tributos; en adelante sólo hubo hombres libres en las ciudades": seria un error inferir que las libertades son otro nombre del gran número.)

La perspectiva dantesca, de visible raigambre aristotélico-escolástica, remite complementariamente - es el objetivo del locus que utilizamos - a una concepción de la integralidad humana (el hombre como microcosmos) centrada en la variadísima gama de los amores que el sujeto humano es capaz de experimentar.

De uno y otro aspectos daremos muestras textuales a continuación, tanto más necesarias cuanto que, a esta altura de los tiempos, el lenguaje de los poetas, juzgado por los filósofos de profesión, parece no poder aspirar más que a ser pintoresco.

(a) El cuadro general del argumento es el de las "potencias del alma", las cuales se escalonan en la serie jerárquica: vida, sensibilidad, entendimiento (¿también locomoción?: Dante la asimila al segundo nivel). He aquí la explanación que el artista dedica al lego de habla vulgar: 


\begin{abstract}
"Según lo que el Filósofo dice, es evidente a todas luces que estas potencias están relacionadas entre sí de tal modo, que una es fundamento de la otra; y la potencia que sirve de fundamento puede por si sola quedar separada; pero lá otra, que se funda sobre ésta, no puede quedart separada de ella. Por eso la potencia vegetativa, por la cual vivimos, es el fundamento sobre el que se levanta el sentido...; y esta potencia vegetativa por si sola puede ser alma, como sucede en todas las plantas. La potencia sensitiva sin la anterior no puede existir: y no se encuentra en los seres carentes de vida; y esta potencia sensitiva es a su vez fundamento de la intelectual, esto es, de la razón [...] Y el alma que tiene todas estas potencias y es la más perfecta de todas es el alma humana, la cual, con la nobleza de la potencia última, es decir, la razón, participa de la divina naturaleza a manera de inteligencia sempiterna, porque el alma se encuentra tan ennoblecida y despojada de toda materia en aquella soberana potencia, que la luz divina irradia sobre ella como sobre un ángel, y por esto el hombre ha sido llamado por los filósofos animal divino".
\end{abstract}

Como se advierte, Dante está tan seguro de la irreductibilidad de lo superior respecto de lo inferior o "fundamental" - lo que equivale al reconocimiento de la dignidad del hombre - que no teme repetir, con machacona pedagogía, que la escala de las potencias conforma una continuidad, a la vez, sin rupturas y sin epifenomenismo de lo superfluo. Lo que sigue ratificará esta certidumbre.

(b) "Superior, en vez de designar ajenidad respecto de los demás órdenes de existencia, menta, al contrario, universal participación en todos ellos. El ente más complejo y elevado demuestra serlo acrecentando sus posibilidades vinculatorias, es decir, sus posibilidades de amor (véase cap. iii). "Los hombres tienen un amor específico suyo a cosas perfectas y honestas. Y, como el hombre, aunque es una sola sustancia, sin embargo, la forma, por su nobleza, participa de la naturaleza de cada una de estas cosas, puede tener, y de hecho tiene, todos estos amores".

Dante enumera con prolijidad esa plenitud de participación. Nos bastará con extraer del texto algunas de las expresiones de la integralidad del hombre.

" [...] Por la naturaleza tercera, es decir, la de las plantas, tiene el hombre amor a cierto alimento (no en cuanto sensible, sino en cuanto es nutritivo) [...] Por la naturaleza cuarta, la de los animales, es decir, la sensitiva, tiene el hombre otro amor por el cual ama según las aparencias sensibles, como los animales; y este amor tiene en el hombre extraordinaria necesidad de guía por sus excesos en la operación, principalmente en los deleites del gusto y del tacto. Y por la quinta y última naturaleza, o sea la verdaderamente humana o, por mejor decir, angélica, esto es, racional, tiene el hombre amor a la verdad y a la virtud".

Así, todo va a dar a un arte de vida. Pues, lo que quisiéramos retener, al concluir, aun a riesgo de aparecer afiliados al bando de los sermoneadores, es que, puesto que somos naturalmente aptos para el ineluctable amor animal, no hemos de condenarnos a serlo sólo para él. La polémica en torno al reduccionismo no se desarrola sin afectar al plano de la más inmediata cotidianeidad: es, quizás, la astucia de los debates de ideas que en la superficie se exhiben desasidos de lo más real. 